\title{
Repeated circulatory arrest under hypothermia
}

\author{
VIKING OLOV BJÖRK AND SETH HÖGSTR ÖM \\ From the University Hospital, Uppsala, Sweden
}

In cases of pulmonary valvular stenosis without infundibular constriction and in cases of atrial septal defect with or without abnormal venous return we continue to use inflow occlusion under hypothermia $\left(29\right.$ to $31^{\circ} \mathrm{C}$.) in preference to extracorporeal circulation. The reason for this is that a small but significant mortality rate must be ascribed to the perfusion technique per se, whereas in our experience the same risk does not follow a well-conducted hypothermia (Björk, Holmdahl, and Petersson, 1960).

If a second period of inflow occlusion is needed to complete the intracardiac part of the operation it is generally recommended that the circulation is restored for a period of twice the length of circulatory arrest before a second arrest is permitted (Zindler, 1957).

The aim of this paper is to explain why no such rule of thumb can be recommended. It is necessary to follow the acid-base balance continuously and to wait until a normal or alkalotic state has again been reached. This may take longer than anticipated and sometimes the addition of sodium bicarbonate may prove valuable. Two cases, one with pulmonary valvular stenosis and atrial septal defect and one with atrial septal defect combined with an abnormal pulmonary venous return, illustrate the value of these principles.

\section{CASE REPORTS}

PATIENT 1 A 3-year-old girl, only $10 \mathrm{~kg}$. in weight, with a systolic murmur and right ventricular hypertrophy, was found to have a high pressure of $130 \mathrm{~mm} . \mathrm{Hg}$ in the right ventricle at cardiac catheterization. No shunt was demonstrated. Angiocardiography showed an isolated pulmonary valvular stenosis and suggested an atrial septal defect.

After induction of anaesthesia with oxygen, nitrous oxide, and halothane the patient was connected to an Engström respirator for controlled respiration. Halothane was withdrawn and after curarization she was cooled in a bath. At the start of the operation arterial blood analysis at $31^{\circ} \mathrm{C}$. showed satisfactory oxygenation and

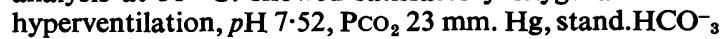

$19 \mathrm{mEq} / \mathrm{l}$. and $\mathrm{Po}_{2} 97 \mathrm{~mm}$. $\mathrm{Hg}$ (Fig. 1). At $29^{\circ}$ C. a median sternotomy was performed and both venae cavae were isolated. After opening the pericardium a significant right-to-left shunt developed with a rapid deterioration in the patient's condition.

In spite of pure oxygen, hyperventilation, and $15 \mathrm{mEq}$ sodium bicarbonate $(25 \mathrm{ml}$. $5 \%$ solution), the arterial blood showed a relatively low oxygen tension with $\mathrm{Po}_{2}$ $115 \mathrm{~mm} . \mathrm{Hg}, p \mathrm{H} \mathrm{7} 32, \mathrm{PCO}_{2} 29 \mathrm{~mm}$. Hg, and stand. $\mathrm{HCO}^{-}$ $15.0 \mathrm{mEq} / \mathrm{l}$. An inflow occlusion for 2 minutes 45 seconds was immediately performed and two commissures of the fused pulmonary valves were opened via the pulmonary artery under direct vision. After restoration of the cir-
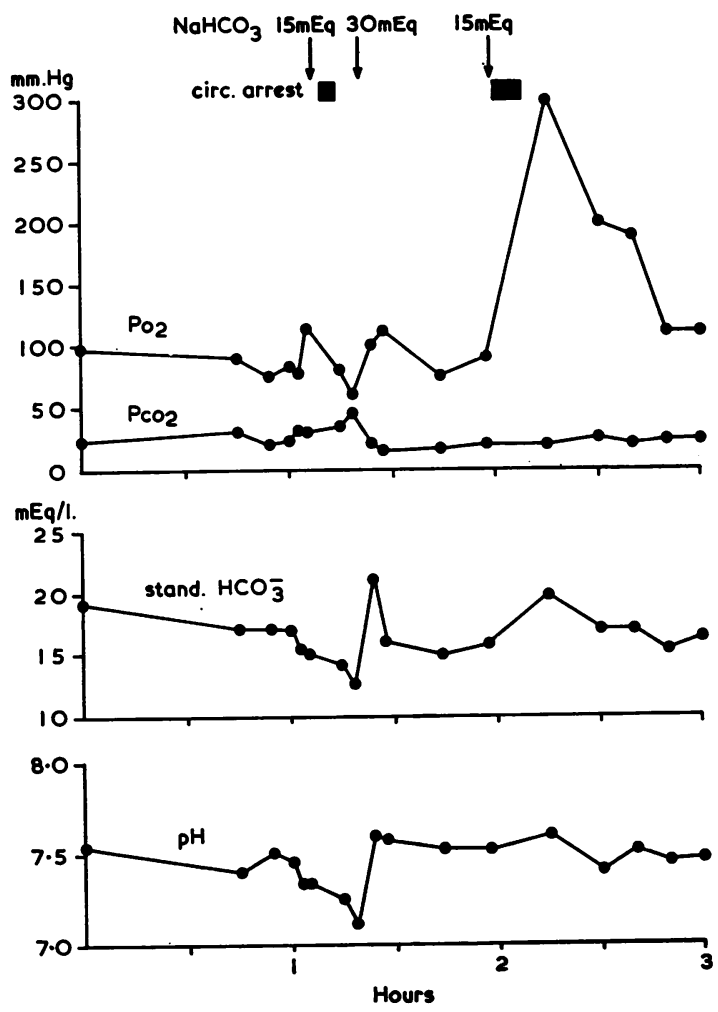

FIG. 1. Patient 1. 
culation the patient was ventilated with pure oxygen. She developed a rapidly increasing acidosis. In three minutes the acid-base values changed from $p \mathrm{H} 7 \cdot 22, \mathrm{PCO}_{2} 35 \mathrm{~mm}$. $\mathrm{Hg}$, stand. $\mathrm{HCO}^{-}{ }_{3} 14.0 \mathrm{mEq} / \mathrm{l}$., $\mathrm{Po}_{2} 81 \mathrm{~mm}$. $\mathrm{Hg}$ to $\mathrm{pH} 7.09$, $\mathrm{PCO}_{2} 44 \mathrm{~mm}$. $\mathrm{Hg}$, stand. $\mathrm{HCO}_{3}^{-} 12.5 \mathrm{mEq} / \mathrm{l}$. and $\mathrm{Po}_{2}$ $60 \mathrm{~mm}$. Hg. Thirty milliequivalents sodium bicarbonate was given immediately and later a further $15 \mathrm{mEq}$. One hour after the first arrest the $p \mathrm{H}$ had stabilized at $7 \cdot 50$, $\mathrm{PCO}_{2} 19 \mathrm{~mm}$. $\mathrm{Hg}$, stand. $\mathrm{HCO}_{3}^{-} 15.5 \mathrm{mEq} / \mathrm{l}$. and $\mathrm{Po}_{2}$ $89 \mathrm{~mm}$. $\mathrm{Hg}$. A second inflow occlusion was then performed for six minutes and a large secundum defect closed by one running and four isolated sutures. During this occlusion $250 \mathrm{ml}$. oxygenated blood was given for coronary perfusion into the root of the aorta. Curiously the $p \mathrm{H}$ one minute after this arrest was as high as $7 \cdot 59$ with $\mathrm{PCO}_{2} 19 \mathrm{~mm}$. $\mathrm{Hg}$, stand. $\mathrm{HCO}_{3}^{-} 19.5 \mathrm{mEq} / \mathrm{l}$. and $\mathrm{Po}_{2}>300 \mathrm{~mm}$. $\mathrm{Hg}$, later changing to $p \mathrm{H} \mathrm{7 \cdot 40,} \mathrm{PCO}_{2}$ $26 \mathrm{~mm}$. Hg, stand. $\mathrm{HCO}_{3}^{-} 16.5 \mathrm{mEq} / \mathrm{l}$. and $\mathrm{Po}_{2}>200 \mathrm{~mm}$. $\mathrm{Hg}$. After closure of the atrial septal defect there was no difficulty with the oxygenation and acid-base balance.

After the operation the patient had a significantly slow cerebration and her spontaneous ventilation was inadequate although there were no signs of continued curarization. A tracheostomy was performed and respirator treatment was given for 24 hours. After that the patient showed no signs of cerebral damage. She was able to take over respiration herself and the tracheal cannula was removed. Further recovery was uneventful.

PATIENT 2 A 16-year-old boy with fatigue as a general symptom and with systolic and diastolic murmurs was found to have a big left-to-right shunt at the atrial level. The oxygen saturation was $67 \%$ in both the inferior and
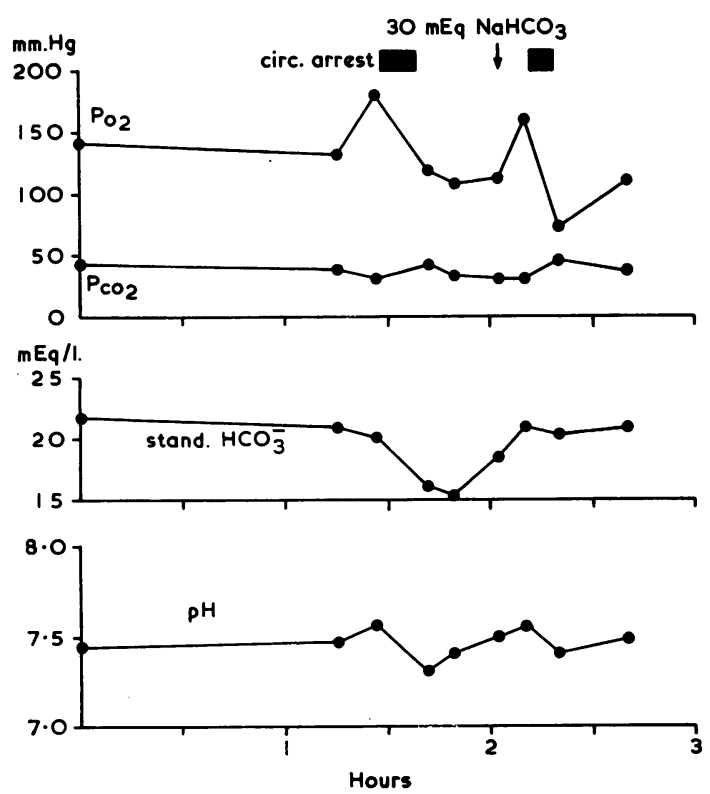

FIG. 2. Patient 2. superior caval veins and $82 \%$ in the pulmonary artery. The pre-operative diagnosis was atrial septal defect with abnormal venous return.

At $30^{\circ} \mathrm{C}$. a right thoracotomy was performed under the fourth rib. The right superior pulmonary vein was divided into two branches, one entering the superior caval vein and the other the right atrium opposite a high atrial septal defect. The superior vena cava was divided lengthwise by an external partitioning with the aid of a ring-clamp to provide two openings into the right atrium, one for the superior vena cava and the other for the abnormal pulmonary vein. During inflow occlusion the edge of the pulmonary vein was sutured to the septal defect. A coronary perfusion of $250 \mathrm{ml}$. oxygenated blood was given into the root of the aorta. The continuous suture ruptured and another was inserted and tied to the first. After 9 minutes 29 seconds the circulation was restored.

According to repeated acid-base determinations (Fig. 2) a delay of 35 minutes and the injection of $30 \mathrm{mEq}$ sodium bicarbonate were required to establish optimal conditions for a second inflow occlusion (6 minutes 7 seconds). Five additional mattress sutures were inserted and the patient was rewarmed in the bath. Recovery was uneventful.

\section{DISCUSSION}

During an inflow occlusion of six to nine minutes at $30^{\circ} \mathrm{C}$. for the closure of an atrial septal defect the $p \mathrm{H}$ will usually drop about $\mathbf{0 . 2}$ unit, depending mainly on a metabolic acidosis. To counteract the untoward effects of the acidosis per se, the high risk of ventricular fibrillation, dilatation of the peripheral vessels, elevation of the pulmonary vascular resistance, as well as other factors, we prefer to start the inflow occlusion at a $p \mathrm{H}$ of 7.5 in order to obtain a final $p \mathrm{H}$ of $7 \cdot 3$ immediately after release of the occlusion. Normally the acidosis disappears spontaneously. Before a second inflow occlusion is undertaken we prefer to have a normal acid-base balance and again a $p \mathrm{H}$ of 7.5 is aimed at. This cannot always be achieved after a short period of circulation.

In the patients described it was necessary to wait 60 and 35 minutes respectively and to give sodium bicarbonate before a second inflow occlusion could be undertaken.

Also in other cases of cardiac arrest it is necessary to pay attention to the metabolic acidosis during prolonged cardiac massage. In one of our patients ventricular fibrillation occurred during right heart catheterization. Under massage the $p \mathrm{H}$ had dropped to 7.06 and the stand. $\mathrm{HCO}^{-}{ }_{3}$ to $6.5 \mathrm{mEq} / 1.30$ minutes after arrest. During one hour a total of $120 \mathrm{mEq}$ sodium bicarbonate was given in repeated doses under control of acid-base balance. The values 
became almost normal and after tracheostomy and respirator treatment for some days the patient made an uneventful recovery.

\section{SUMMARY}

When a second period of inflow occlusion during hypothermia is desired, we think it is imperative to wait until the acid-base balance is brought back to optimal values before the second circulatory arrest is performed. This optimum may not be obtained merely by a short period of circulation and hyperventilation. The best way is to observe the acid-base balance in the arterial blood. Sometimes sodium bicarbonate may prove valuable.

Two cases are reported as examples of these principles. A case of cardiac arrest is mentioned as an example of the importance of studying the acid-base situation and the value of sodium bicarbonate in large doses given rapidly.

\section{REFERENCES}

Björk, V. O., Holmdahl, M. H. son, and Petersson, P. O. (1960). Acta chir. Scand., 119, 317.

Zindler, M. (1957). In Handbuch der Thoraxchirurgie, ed. E. Derra, Vol. 1, p. 666. Springer, Berlin. 